\title{
OBLIGACIONES Y RESPONSABILIDAD CIVIL
}

Patricia López Díaz

Profesora de Derecho Civil

Universidad de Valparaíso

Publicidad engañosa. Indemnización de daños. Concurrencia de ResPonSABILIDAD CIVIL. OPCIÓN DE RESPONSABILIDADES. RESPONSABILIDAD EXTRACONtractual. Corte Suprema, 18 de enero de 2018, rol 73907-2016. Cita en LÍNEA VLEX-701344085*.

Con fecha 18 de enero de 2018, la Corte Suprema, conociendo de un recurso de casación en la forma y en el fondo interpuesto por el Instituto Nacional Santo Tomás en contra de la sentencia de la Corte de Apelaciones de Valparaíso, rechazó el primero y acogió el segundo, otorgando a los demandantes la indemnización de daños derivada de la publicidad engañosa en la que este incurrió al ofertar la carrera de Técnico Perito Forense e Investigación Criminalística, retomado el razonamiento del tribunal de primera instancia y desestimando el de segunda que denegó la indemnización reclamada, aduciendo que ella era de naturaleza contractual y que no había tenido lugar la integración publicitaria que podría haberla hecho prosperar.

Esta sentencia es interesante, al menos, por tres razones. En primer lugar, parece reiterar, aunque oblicuamente, la premisa asentada por nuestra doctrina y jurisprudencia durante los últimos años, según la cual los juicios valorativos contenidos en los mensajes publicitarios no se integran al contrato celebrado, dado que no se trata de un contenido objetivo o informativo, sino subjetivo o persuasivo, de modo que no tienen la virtualidad de inducirlo a error o engaño ${ }^{1}$. Por otro lado, permite constatar que el régimen de responsabilidad civil extracontractual puede ser mucho más beneficioso para el demandante en aquellos supuestos en que no sea posible integrar la publicidad engañosa al contrato, toda vez que si acredita el daño obtendrá la reparación de la que la improcedencia de la integración publicitaria lo priva. Finalmente, evidencia que el reconocimiento jurisprudencial de la opción de responsabilidades, que tuvo lugar con ocasión de la sentencia pronunciada por la Corte Suprema el 21 de

\footnotetext{
*Este comentario ha sido sometido a peer review. Recibido el 14 de marzo de 2018 y aceptado para su publicación el 24 de abril de 2018.

${ }^{1}$ Momberg (2007), p. 607 y De la Maza (2013b), p. 445 y Celedón Fernández con Corporación Santo Tomás (2012); González Valenzuela con Corporación Santo Tomás (2012) y Zuñiga Castro con Instituto de Educación Superior Santo Tomás (2016).
} 
marzo de 2016 en Fernández con Arinoviche y otros², tiene un alcance amplio, pues no se circunscribe exclusivamente a la responsabilidad médica, sino a todo supuesto en que concurran la indemnización contractual y extracontractual ${ }^{3}$, como acontece en el presente caso.

Por consiguiente, su análisis nos llevará a explorar la publicidad engañosa como hecho generador de responsabilidad civil y a constatar que la admisibilidad de la opción de responsabilidades en nuestra jurisprudencia reciente abre una estrategia de defensa más conveniente para el destinatario de aquella, pues si solo pretende la indemnización de daños (y no activar los medios de tutela por incumplimiento contractual) le resultará más adecuado inclinarse por el régimen extracontractual, toda vez que, como se trata de un supuesto de responsabilidad objetiva ${ }^{4}$, ni siquiera debe acreditar la imputabilidad del anunciante, sino que basta con probar el daño ocasionado.

\section{LOS HECHOS: \\ LA PUBLICIDAD ENGAÑOSA REFERIDA AL CAMPO LABORAL de la carrera de Técnico Perito Forense E InVESTIGACIÓN CRIMINALÍstica}

Los hechos acontecidos son idénticos a los conocidos por la Corte Suprema 196 en Celedón Fernández con Corporación Santo Tomás y González Valenzuela con Corporación Santo Tomás el 11 de mayo de $2012^{5}$ y en Zuñiga Castro con Instituto de Educación Superior Santo Tomás el 21 de julio de $2016^{6}$.

Sin embargo, la estrategia seguida por el demandante en este caso fue diversa y, por lo mismo, obtuvo, en definitiva, sentencia favorable. Conviene, por tanto, consignarlos, al igual que el razonamiento de los jueces de primera y segunda instancia, para determinar cuál de ellos es acertado y coincidente con el sustentado por la Corte Suprema.

Con fecha 14 de enero de 2016 el Segundo Juzgado Civil de Viña del Mar acogió la demanda deducida por María José Ugarte y otros en contra del Instituto Profesional Santo Tomás en virtud de la cual solicitan que este último les indemnice los daños derivados de la publicidad engañosa relativa al campo ocupacional de la carrera de Técnico Perito Forense e Investigación Criminalística, establecida por sentencia de 31 de agosto de 2010 del Tercer

\footnotetext{
${ }^{2}$ Fernández con Arinoviche y otros (2016).

${ }^{3}$ Como ya lo había denunciado Corral (2016).

${ }^{4}$ Morales (2006b), pp. 228, 246 y 251 y De la Maza (2013a), p. 660.

${ }^{5}$ Comentados en esta revista ese mismo año por el profesor Iñigo de la Maza (DE LA MAZA (2012), pp. 209-213). Véase, respectivamente, Celedón Fernández con Corporación Santo Tomás (2012) y González Valenzuela con Corporación Santo Tomás (2012).

${ }^{6}$ Zuñiga Castro con Instituto de Educación Superior Santo Tomás (2016).
} 
Juzgado de Policía Local de Viña del Mar ${ }^{7}$ y confirmada, en esa parte, por la Corte de Apelaciones de Valparaíso el 4 de abril de $2012^{8}$.

El referido anuncio indicaba que "la Reforma Procesal Penal augura un gran campo ocupacional y muy interesantes expectativas para los peritos forenses", agregando que el investigador criminalístico y el perito forense podrán desempeñarse

"en laboratorios de criminalística públicos y privados, como asesor de Fiscales del Ministerio Público o de la Defensoría Pública, como asesor de Oficinas de abogados y ejercicio libre de la profesión".

No obstante, a diferencia de los casos ya referidos y, al igual como aconteció en Santos Pastenes y otros con Corporación Santo Tomás ${ }^{9}$ resuelto por la Corte Suprema el 12 de diciembre de 2012, el Tercer Juzgado de Policía Local de Viña del Mar tuvo por acreditada la publicidad engañosa, invocando al efecto la infracción de los arts. 23, 28 b) y c) ${ }^{10}$ y 33 de la ley $\mathrm{N}^{0} 19.496$ sobre protección de derechos de los consumidores, disponiendo, además del pago de la multa pertinente, la indemnización de los daños patrimoniales y morales derivados de dicho ilícito civil.

El distinto pronunciamiento al que se arribó en estos dos últimos casos encuentra explicación en el hecho de que el campo laboral publicitado fue susceptible de verificación, por cuanto la respuesta a los oficios emitidos por el tribunal a las diferentes entidades involucradas permitieron constatar que este era inexistente en ellas ${ }^{11}$, de modo que, salvo en lo que concierne al desempeño como asesores de oficinas de abogados y ejercicio libre de la profesión ${ }^{12}$, el mensaje publicitario no solo indujo a error o engaño a sus destinatarios sino que dejó de ser una mera opinión o juicio de valor ${ }^{13}$. Y es que como lo ha precisado acertadamente nuestra doctrina, el elemento determinante de la publicidad engañosa no es la falsedad del mensaje, sino su idoneidad para inducir a error o a engaño ${ }^{14}$.

En el caso que se comenta, solo algunos de los actores obtuvieron reparación ante el Juzgado de Policía Local, pues las demandas entabladas por los

${ }^{7}$ Que la condenó al pago de una multa de 30 UTM y a la indemnización de daños respecto de otros actores. Véase Vidal Riquelme con Instituto Santo Tomás (2010).

${ }^{8}$ Vidal Riquelme con Instituto Santo Tomás (2012).

${ }^{9}$ Santos Pastenes y otros con Corporación Santo Tomás (2012).

${ }^{10}$ Que indica como condiciones objetivas, respectivamente, "la idoneidad del bien o servicio para los fines que se pretende satisfacer, atribuida en forma explícita por el anunciante" y "las características relevantes del bien o servicio destacadas por el anunciante o que deban proporcionarse como información comercial".

${ }^{11}$ Considerandos $30^{\circ}$ a $52^{\circ}$ de la sentencia Vidal Riquelme con Instituto Santo Tomás (2010).

${ }^{12}$ Campo laboral que, en opinión del tribunal, queda dentro de las posibilidades inherentes a cualquier profesión liberal, motivo por el cual no puede calificarse de engañosa ni inductiva a error. Véase el considerando $42^{\circ}$ de la sentencia Vidal Riquelme con Instituto Santo Tomás (2010).

${ }^{13}$ De la Maza (2015), p. 563.

${ }^{14}$ De la MaZa (2013a), pp. 656-657. 
restantes no fueron notificadas dentro del plazo de cuatro meses contados desde su presentación, circunstancia que, de conformidad al inciso cuarto del art. 9 de la ley $\mathrm{N}^{\mathrm{O}} 18.297$, que establece el procedimiento ante los juzgados de policía local, faculta a los demandantes para sustentar su pretensión indemnizatoria en sede civil. Invocando tal artículo entablaron demanda de responsabilidad civil extracontractual ante el Segundo Juzgado Civil de Viña del Mar, fundándola en la vulneración de los arts. 2314, 2284 y 2319 del Código Civil, expresando que fueron alumnos de la referida carrera entre los años 2004 y 2007 y durante ese periodo debieron incurrir en diversos gastos destinados a financiarla ${ }^{15}$ que reclaman bajo el acápite de daño emergente, pues lejos de significar una inversión se transformaron en un pasivo, dado que debieron soportarlos en su totalidad. Consignan que, además de tales perjuicios, experimentaron daño moral, ya que se vieron expuestos a burlas por haber confiado en un futuro laboral promisorio, perdiendo tres años de estudio inútilmente, descuidando sus respectivos trabajos y familias y experimentando, en definitiva, depresión $\mathrm{y}$ angustia por haber truncado sus sueños profesionales.

Agregan que la relación de causalidad entre el ilícito civil y los daños que demandan fue establecida por el Tercer Juzgado de Policía Local de Viña del Mar, porque de no haber mediado publicidad engañosa los demandantes no se habrían matriculado en una carrera que carecía de campo laboral. Finalmente, precisan que el procedimiento aplicable es el sumario, dado que el art. 19850 B de la ley $\mathrm{N}^{\mathrm{o}} 19.496$ dispone que, en lo no previsto por ella, se aplica la ley $\mathrm{N}^{\mathrm{o}} 18.297$ y, en su defecto, como ocurre en el presente caso, el Código de Procedimiento Civil, específicamente el art. 680 y siguientes.

El Instituto demandado, por su parte, sostiene que no existe título que justifique la indemnización solicitada, toda vez que la sentencia infraccional no fue apelada por los demandantes en cuanto a la indemnización ni tampoco efectuaron reserva de derechos. Añaden que no se configuró incumplimiento contractual o ilícito que la hiciera procedente, ya que la carrera se impartió en los términos ofrecidos, cumpliendo con los programas y planes de estudio convenidos y existiendo el campo ocupacional publicitado, como lo revela el hecho de que muchos de los titulados se desempeñaban como peritos en diversas Cortes de Apelaciones del país, y que los actores se enriquecieron con los conocimientos y habilidades adquiridas con la prestación educacional ofrecida.

También aduce que el tribunal civil carece de competencia en lo que al daño moral se refiere, pues el único competente es el juez de policía local o el juez civil, tratándose de una acción colectiva, hipótesis que no se configuran en el caso de autos. Por último, indican que la acción está prescrita, por cuanto han transcurrido siete años desde la dictación de la sentencia infraccional, de modo que ha expirado el plazo de cinco años que contempla el art. 2515 del Código Civily el de seis meses previsto en el art. 26 de la Ley No 19.496.

${ }^{15}$ Tales como el pago del arancel, matrícula, colegiatura anual, crédito educacional con subsidio CORFO, útiles escolares, materiales de estudio, fotocopias, alimentación y gastos de traslado. 
El tribunal de primera instancia desestima las alegaciones del demandado y acoge la pretensión resarcitoria. A tal efecto indica que es improcedente la excepción de prescripción alegada, pues el inciso quinto del art. $5^{\circ}$ de la ley $\mathrm{N}^{\circ} 18.297$ señala, en lo que aquí interesa, que si no se hubiera interpuesto demanda civil

"podrá interponerse ante el juez ordinario que corresponda, después que se encuentre ejecutoriada la sentencia que condena al infractor, suspendiéndose la prescripción de la acción civil de indemnización durante el tiempo de sustanciación del proceso infraccional. Esta demanda se tramitará de acuerdo a las reglas del juicio sumario, sin que sea aplicable lo dispuesto en el artículo 681 del Código de Procedimiento Civil”.

Dicha regla, precisa el tribunal, constituye una excepción a aquella que regula la prescripción prevista en el art. 2332 del Código Civil y ratifica que no se completó el plazo de prescripción de la acción.

A continuación, resuelve el fondo de la cuestión debatida, acogiendo la demanda interpuesta. En primer lugar, señala que el Juzgado de Policía Local consignó, en el considerando $53^{\circ}$ de su sentencia, que las demandas de los actores "debían tenerse por no presentadas", dado que no fueron notificadas dentro del plazo de cuatro meses de su ingreso, como lo exige el inciso cuarto del art. 9 de la ley $\mathrm{N}^{\mathrm{o}}$ 18.297, admitiendo el derecho de los actores para "recurrir a la justicia ordinaria". En consecuencia, indica, dicha sentencia que condenó a la demandada por el ilícito civil de publicidad engañosa y respecto de la cual existe cosa juzgada, constituye el título que los actores esgrimen como consecuencia de su acción.

Sostiene, además, que en el presente juicio los demandantes acreditaron el daño emergente y moral reclamados, pues, si bien incurrieron en diversos gastos no recibieron como contrapartida el servicio prometido, lo que les impidió lucrar y desarrollar alguna actividad remunerada con los conocimientos impartidos, circunstancia que les causó angustia, depresión y molestias por no alcanzar sus sueños profesionales ${ }^{16}$.

Frente a esta sentencia adversa, el demandado interpuso recurso de apelación ante la Corte de Apelaciones de Valparaíso, que fue acogido por dicho tribunal en sentencia de 25 de Julio de $2016^{17}$, revocando, en consecuencia, la sentencia de primera instancia. El argumento esgrimido por dicho tribunal fue que la ley $\mathrm{N}^{\mathrm{o}} 19.496$ establece entre el consumidor y el proveedor una relación de carácter contractual, razonamiento que habría seguido la sentencia apelada al reconocer que la demandada incumplió la prestación de los servicios educacionales convenidos, considerando, en consecuencia, que la indemnización impetrada es de naturaleza contractual, de modo que su procedencia debería

${ }^{16}$ Ugarte y otros con Instituto Profesional Santo Tomás (2016), Segundo Juzgado Civil de Viña del Mar.

${ }^{17}$ Op. cit., Corte de Apelaciones de Valparaíso. 
haberse abordado desde aquella arista. Tal análisis, en opinión del tribunal, habría conducido al juzgado civil a desestimar la pretensión indemnizatoria, toda vez que el contenido subjetivo o persuasivo del mensaje publicitario no se integra al contrato. En tal sentido expresa, en el considerando séptimo, lo siguiente: "Que efectivamente la jurisprudencia del máximo Tribunal ha sostenido reiterada e invariablemente que el incumplimiento de la obligación contractual que estiman no cumplida los estudiantes -autores de autos- consistente en la falta de campo laboral ofrecido no se encuentra expresamente señalado en el contrato de prestación de servicios. Agrega, que el valor subjetivo de la publicidad impide considerarla integrada al contrato de prestación de servicios educacionales, no configurándose la obligación que se estima infringida. Además, señala que la obligación de verificar la existencia del campo ocupacional para la carrera de Técnico Perito Forense e Investigación Criminalística, no es un elemento de la naturaleza del contrato" ${ }^{18}$.

En contra de esta sentencia el demandante deduce recurso de casación en la forma, denunciando la omisión del asunto controvertido y ultrapetita, y recurso de casación en el fondo, rechazándose el primero y acogiéndose el segundo por la Corte Suprema en sentencia de 18 de enero de 2018. Dicho tribunal, acertadamente, reconduce la discusión a la responsabilidad civil 200 extracontractual, pronunciándose, además, sobre la procedencia de la opción de responsabilidades.

Sin embargo, antes de abordar tal razonamiento, nos referiremos a la tutela que puede impetrarse en el supuesto de publicidad engañosa, distinguiendo las diversas hipótesis que pueden presentarse con el propósito de fijar, dogmáticamente, los diversos escenarios en que transitaron los tribunales de instancia y cotejarlos, al finalizar este comentario, con aquel escogido por la Corte Suprema.

\section{LA PUBLICIDAD ENGAÑOSA COMO HECHO GENERADOR DE RESPONSABILIDAD CIVIL: ¿TUTELA PRECONTRACTUAL, CONTRACTUAL O EXTRACONTRACTUAL?}

Como es bien sabido, la publicidad engañosa constituye un ilícito infraccional ${ }^{19}$. Así se desprende, en lo que aquí interesa ${ }^{20}$, del art. 28 de la ley $\mathrm{N}^{\circ} 19.496$ que, al describir el supuesto de hecho que la configura, indica:

${ }^{18}$ Sentencia rol $\mathrm{N}^{\circ} 8532-10$ de 10 de mayo de 2012; rol N 17.108 de 2013, 18 de diciembre de 2014; rol N 23.951-2014, de 8 de abril de 2015.

${ }^{19}$ Un análisis de la publicidad engañosa en la doctrina nacional en IsLER (2010), pp. 125-148 y De la Maza (2013a), pp. 653-671.

${ }^{20}$ Pues el art. 28A tipifica como infracción la confusión producida a los consumidores, a través de cualquier tipo de mensaje publicitario, respecto de la identidad de empresas, actividades, productos, nombres, marcas u otros signos distintivos de competidores. 
"comete infracción a las disposiciones de esta ley el que, a sabiendas o debiendo saberlo y a través de cualquier tipo de mensaje publicitario induce a error o engaño"

respecto de algunas de las condiciones objetivas que dicho precepto señala. Tal infracción se sanciona, de conformidad al art. 24, con una multa que va desde las 50 a las 100 UTM, pudiendo elevarse al doble en caso de reincidencia, sin perjuicio de impetrar la medida prejudicial preparatoria indicada en el art. 34 y solicitar al juez que exija al medio de comunicación utilizado en la difusión de los anuncios o a la correspondiente agencia de publicidad, la identificación del anunciante o responsable de la emisión publicitaria.

Sin embargo, también constituye un ilícito civil, en la medida que cause daños al destinatario de la publicidad. E, incluso, como se examinará más adelante, una anomalía precontractual. De allí que el art. $3^{\circ}$ letra e) de la ley $\mathrm{N}^{\mathrm{O}} 19.496$ contemple como derecho del consumidor "la reparación e indemnización adecuada y oportuna" y el inciso segundo del art. 50 prescriba que el incumplimiento de las normas contenidas en dicha ley dará lugar, entre otras varias medidas, a obtener "la debida indemnización de perjuicios o la reparación que corresponda".

Se trata, como lo ha precisado la dogmática comparada y nacional ${ }^{21}$, de un supuesto de responsabilidad objetiva que encuentra su fundamento en el riesgo creado y que se sustenta en la siguiente regla: quien emite un mensaje publicitario debe asumir, en alguna medida, la frustración de la confianza creada. De allí que resulte irrelevante que el anunciante haya sabido o haya debido saber que induce a error o a engaño, adquiriendo relevancia su diligencia exclusivamente para efectos infraccionales ${ }^{22}$.

Las hipótesis de publicidad engañosa que hasta la fecha ha conocido nuestra jurisprudencia son diversos. Además del que venimos refiriendo, destacan, entre otros, la publicidad de un sorteo organizado por una empresa con un pozo estimado a repartir superior al real, la ausencia de ginseng coreano rojo en un producto ofertado como tal, la posibilidad de efectuar el pago de una deuda en un número de cuotas que el sistema computacional no admite, la diferente superficie publicitada de un predio en comparación a la real y la oferta de una alarma con grabación de imágenes " 24 horas" que solo tenía lugar cuando ella se activaba ${ }^{23}$.

En todos ellos, ciertamente existe publicidad engañosa, advirtiéndose, según el caso, dolo del anunciante o un error provocado en el destinatario de la publicidad que lo conducirán a celebrar un contrato de adquisición de bienes o contratación de servicios en razón de ella. Con todo, también podría configurarse un ilícito civil o un problema de incumplimiento contractual.

${ }^{21}$ Morales (2006 b), pp. 228, 246 y 251. En similar sentido De la MaZa (2013a), p. 660.

${ }^{22}$ De la Maza (2013a), p. 661.

${ }^{23}$ Un completo análisis de todos ellos en De la MAZA (2013a), pp. 660-670, De LA MAZA (2013 b), pp. 445-447 y 449-451 y DE LA MAZA (2015), pp. 557-571. 
Miradas las cosas desde esta perspectiva, pareciera que la tutela por publicidad engañosa puede reconducirse a la fase precontractual (nulidad relativa e indemnización complementaria a ella), a la fase contractual (medios de tutela por incumplimiento) o simplemente a la responsabilidad civil extracontractual (indemnización de daños).

La pregunta que surge entonces es la siguiente: ¿̇cuál es más conveniente? La respuesta dependerá del supuesto concreto en que nos encontremos. Y el caso objeto de la sentencia que venimos comentando es un buen ejemplo de ello, porque, como se acreditó en el juicio sustanciado en sede de consumo que el campo laboral publicitado era inexistente en las instituciones aludidas en el anuncio publicitario, el demandante, a diferencia de los casos anteriores en que también fue demandado el Instituto Santo Tomás, no solo podría inclinarse por la responsabilidad extracontractual o la nulidad relativa del contrato, sino por la integración publicitaria, toda vez que el campo laboral al ser verificable efectivamente era inductivo a error o a engaño. Dicho de otra forma, disponía de todas las estrategias de protección posibles.

Un detenido análisis de la publicidad engañosa revela que existen, al menos, dos cuestiones relevantes que deben tenerse a la vista para definir tal estrategia $\mathrm{y}$, por consiguiente, la tutela que se pretende alcanzar. Podría pensarse que la primera es si existe contrato, pero lo cierto es que puede ocurrir que, existiendo este, el acreedor deseche recurrir a la tutela contractual. Por consiguiente, la primera pregunta es, en realidad, si existiendo contrato, el destinatario de la publicidad quiere integrarla a él para configurar una falta de conformidad que le permita activar los medios de tutela por incumplimiento. La segunda es, si desechando tal alternativa, prefiere demandar la nulidad del contrato por error provocado o dolo o, bien, instar por la indemnización extracontractual invocando la existencia de un ilícito civil.

Veamos la primera alternativa. Como es bien sabido, la integración publicitaria surgió en el Derecho Comparado frente a la ausencia de medidas destinadas a tutelar al consumidor frente a la disconformidad existente entre la publicidad engañosa y el contrato celebrado ${ }^{24}$. A una constatación similar puede arribarse tratándose de la ley $\mathrm{N}^{0} 19.496$, toda vez que prevé en el art. 24 una multa infraccional de hasta 1.000 UTM y, en el art. 31, la posibilidad de que el tribunal competente imponga al anunciante, a su propia costa, la realización de la publicidad correctiva destinada a enmendar falsedades o errores. De hecho, el único medio de tutela contractual que regula indirectamente es la indemnización de daños, como lo revela el inciso segundo del art. 50 de la ley. Pero el recurso a ella requiere configurar la hipótesis de incumplimiento o acreditar la anomalía precontractual o el ilícito extracontractual que le sirve de fundamento.

En casos como el que comentamos, los demandantes han recurrido, preferentemente, a la tutela contractual invocando la integración de la publicidad

${ }^{24}$ Morales (2006a), pp. 271-273. 
engañosa al contrato para solicitar la indemnización por incumplimiento de un contrato de prestación de servicios educacionales, argumentando que es obligación del proveedor asegurar la existencia de un campo laboral determinado. Así ha acontecido en Celedón Fernández con Corporación Santo Tomás, González Valenzuela con Corporación Santo Tomás y Zúñiga Castro con Instituto de Educación Superior Santo Tomás ${ }^{25}$.

El fundamento de tal integración se encuentra en el art. $1 \mathrm{~N}^{\circ} 4$ de la ley 19.496 , pues este indica que se entenderán "incorporadas al contrato las condiciones objetivas contenidas en la publicidad hasta el momento de celebrar el contrato", agregando que son "condiciones objetivas" las señaladas en el art. 28 antes referido ${ }^{26}$. Y, como lo ha asentado la dogmática y jurisprudencia nacional, solo se integraría el contenido objetivo o informativo del mensaje publicitario y no el subjetivo o persuasivo ${ }^{27}$, debiendo concurrir tres requisitos al efecto:

i) que el destinatario haya conocido la publicidad,

ii) que tal publicidad sea determinante en su decisión de contratar y

iii) que este confiara razonablemente en ella.

El proveedor solo podría exonerarse de responsabilidad demostrando que no tuvo ni pudo tener razonablemente conocimiento de la declaración al momento de la venta (atendido el tenor del art. 28 que prescribe "sabiendo o debiendo saberlo") y corrigiendo la declaración antes de la celebración del contrato, en el mismo medio y de la misma forma que la declaración original (pues ya no existiría confianza razonable que tutelar) ${ }^{28}$.

De allí que para configurar la falta de conformidad el demandante sostenga en Celedón Fernández con Corporación Santo Tomás, González Valenzuela con Corporación Santo Tomás y Zúñiga Castro con Instituto de Educación Superior Santo Tomás, que el mensaje publicitario "augura un gran campo ocupacional y muy interesantes expectativas para los peritos forenses", era conocido por él y lo indujo a contratar, ya que confió razonablemente en su contenido. Sin embargo, en tales casos, como acertadamente resolvió la Corte Suprema, tal integración era improcedente, porque, como se acreditó que el campo laboral publicitado, era inexistente, la referida frase solo contenía un juicio de valor que no se integra al contrato, pues expresa la posibilidad que llegue a existir ese campo laboral para sus egresados, pero no "lo asegura con algún grado de certeza" 29

${ }^{25}$ Celedón Fernández con Corporación Santo Tomás (2012), González Valenzuela con Corporación Santo Tomás (2012) y Zuñiga Castro con Instituto de Educación Superior Santo Tomás (2016).

${ }^{26}$ Un contundente análisis de tales condiciones en DE LA MAZA (2013 a), pp. 663-670.

${ }^{27}$ Momberg (2007), p. 607 y De la Maza (2013b), p. 445. Véase Celedón Fernández con Corporación Santo Tomás (2012), González Valenzuela con Corporación Santo Tomás (2012) y Zuñiga Castro con Instituto de Educación Superior Santo Tomás (2016).

${ }^{28}$ DE LA MAZA (2013 b), pp. 442-453.

${ }^{29}$ Véase considerando sexto, décimo y quinto de las sentencias pronunciadas, respectivamente, en Celedón Fernández con Corporación Santo Tomás (2012) y Zuñiga Castro con Instituto de Educación Superior Santo Tomás (2016). Un completo análisis de la jurisprudencia chilena en esta materia hasta el año 2015 en DE LA MAZA (2015), pp. 557-571. 
Cuestión distinta es, como aconteció en autos, que se constate tal circunstancia, toda vez que puede integrarse la publicidad engañosa al contrato y activar la tutela contractual. Dicha tutela, al menos en este caso, no consistirá en exigir el cumplimiento específico, pues el Instituto no puede crear un campo laboral que las condiciones de mercado no han logrado generar. En consecuencia, se reconducirá a la resolución, atendido el incumplimiento de la obligación que el contrato garantiza (cual es la existencia de un campo laboral determinado y verificable), acompañada de la indemnización o a la indemnización autónoma. Y las partidas indemnizables serán el daño emergente, el lucro cesante y el daño moral, debiendo requerirse en la primera partida los gastos destinados a financiarla; en la segunda, lo que dejaron de obtener como ingreso por no existir un campo en el que pudieran ejercer su profesión y, en la tercera, la angustia y aflicción que les produjo no realizar sus sueños profesionales.

En aquellos casos en que no proceda la integración publicitaria, surgen como alternativas de protección la tutela precontractual o extracontractual. Tratándose de la primera el destinatario de la publicidad demandará la nulidad por error provocado ${ }^{30}$ o dolo, según exista o no intención de engañarlo, aniquilando el contrato. La diferencia entre ambas causales es que, en la segunda, deberá acreditarse, según lo prescribe el art. 1459 del Código Civil, pero en ambas puede impetrar la indemnización de daños derivada de la declaración de nulidad destinada a satisfacer el interés negativo o en la confianza, esto es, 204 a situar al acreedor en el estado en que se encontraría de no haber contratado. Claro está que los gastos que el demandante alega en sede de incumplimiento como daño emergente, en sede de nulidad quedan absorbidos en el efecto restitutorio de esta y el perjuicio complementario que invoque deviene en lucro cesante y daño moral.

Activar la tutela precontractual, al igual como acontece con la contractual, implica para el demandante desplegar una mayor actividad que aquella que realizaría si pretendiera recurrir a la extracontractual. En efecto, así como en la contractual deberá acreditar, primeramente, la integración publicitaria y, luego, la procedencia del medio de tutela que invoca, en sede precontractual deberá acreditar la procedencia de la nulidad y la configuración del error o la existencia del dolo y, según el caso, la entidad de los daños que reclama. Probablemente por este motivo se recurra excepcionalmente a esta vía de tutela.

$\mathrm{Y}$, la tercera alternativa, es instar, como lo hizo el demandante, por la responsabilidad civil extracontractual, invocando el ilícito civil de publicidad engañosa y la vulneración de los arts. 2314, 2284 y 2319 del Código Civil. Como ha quedado dicho, esta estrategia parece ser la más conveniente. Más aún que, si bien la tutela que se reclama en esta sede, a diferencia de las dos vías examinadas previamente, es exclusivamente resarcitoria, comprenderá los mismos daños que pueden demandarse en sede contractual a título de daño emergente, lucro cesante y daño moral y es equivalente al alcance de

${ }^{30}$ Morales (2006c), p. 298. 
aquella que el demandante puede alcanzar en sede precontractual a través de las restituciones derivadas de la nulidad y la indemnización complementaria por daño emergente y lucro cesante.

\section{La SENTENCIA DE LA CoRTe Suprema: LA PUBLICIDAD ENGAÑOSA COMO UN HECHO GENERADOR DE RESPONSABILIDAD EXTRACONTRACTUAL Y LA OPCIÓN DEL ACREEDOR}

Como ha quedado dicho más atrás, la Corte Suprema desechó el recurso de casación en la forma interpuesto por el demandado, pues estimó que la sentencia recurrida no infringió los arts. $768 \mathrm{~N}^{\circ} 4$ y N 5 y 160 del Código de Procedimiento Civil. Así, sostuvo que dicho tribunal resolvió el asunto controvertido, rechazando la acción interpuesta por estimar que no ésta no era pertinente, y no incurrió en ultrapetita, dado que asume una postura jurídica desfavorable para los demandantes, pero que no es ajena al conflicto sometido a su conocimiento.

Acogió, en cambio, el recurso de casación en el fondo interpuesto por infracción de los arts. 1437, 1545, 1546, 2314, 2316, 2329 del Código Civil y el art. 9 de la ley $\mathrm{N}^{\circ} 18.297$, pero solo en lo que respecta al 2314, instalando correctamente la discusión en sede extracontractual. Y es que la Corte de Apelaciones, al pronunciar su sentencia, invocó una argumentación que no tenía cabida en el caso de autos, toda vez que se alegaba responsabilidad civil extracontractual, situando al acreedor en el escenario más complejo -pues debían concurrir los requisitos propios de la integración publicitaria-, en circunstancias que este optó por una estrategia defensa más simple.

Para acoger la pretensión alegada y rechazar el recurso de casación en el fondo acude a la concurrencia de responsabilidad civil, admitiendo la opción del acreedor, como lo hiciera en sentencia de 21 de marzo de 2016 en Fernández con Arinoviche y otros a propósito de la responsabilidad médica ${ }^{31}$, pero otorgándole un alcance más general que en aquella oportunidad, amplitud que ya había augurado el profesor Hernán Corral, al comentar dicha sentencia, en los siguientes términos:

"La Corte parece limitar la facultad de optar para los supuestos de responsabilidad civil médica, pero la amplitud de los argumentos esgrimidos para rechazar el 'non cumul permite aventurar que la teoría de la opción pueda más adelante hacerse extensiva a otras las materias en las se produce la misma concurrencia o concurso entre las normas de ambos regímenes de resarcimiento de perjuicios (daños por transporte de personas, accidentes del trabajo, lesiones por productos defectuosos, etc.)"32.

\footnotetext{
${ }^{31}$ Fernández con Arinoviche y otros (2016).

${ }^{32}$ Corral (2016).
} 
Así, la Corte Suprema, en el considerando sexto de la sentencia pronunciada en el caso que venimos comentando, expresa lo siguiente:

"El hecho acreditado, una conducta de la demandada reñida con la ley del consumidor, determina que se esté ante un concurso de acciones, pues esa conducta puede calificarse tanto como una hipótesis de incumplimiento contractual como un ilícito extracontractual. Si hay abstracción de dicho vínculo contractual y los demandantes se vieron afectados en su esfera patrimonial y extrapatrimonial es menester situarse en lo que se denomina concurrencia de responsabilidad civil. En estos casos es dable entender que la víctima y al mismo tiempo acreedor pueda optar por el régimen indemnizatorio que le parezca, dado que se verifican las condiciones de ambos estatutos indemnizatorios. En este sentido, al haber optado los demandantes por el régimen extracontractual, con independencia del vínculo contractual que tuvieron con la demandada, ejercieron un derecho de opción que se les debe reconocer. Y, por lo mismo, ala haberse desestimado la demanda sólo por no invocarse el régimen contractual se infringió el artículo 2314 del Código Civil. En el evento que se verifique un ilícito infraccional, que fue objeto de condena judicial y, al mismo tiempo se satisfagan las condiciones tanto de la responsabilidad contractual como extracontractual, la víctima y acreedor tiene derecho a optar por el régimen que mejor le parezca a fin de satisfacer su interés indemnizatorio" ${ }^{33}$.

Por tal motivo, en el considerando segundo de la sentencia de reemplazo, dicho tribunal consigna:

"Que habiéndose ejercido por los demandantes una acción de naturaleza extracontractual, debe desestimarse la excepción relativa a que la pretensión corresponde resolverla conforme al estatuto contractual. Además, al haberse acreditado el daño demandado y fijado en forma prudencial el daño moral, no corresponde acceder a lo apelado en este ámbito, pues aparece conforme a la prueba rendida en autos, según se acreditó en la sentencia recurrida. Sin embargo, en lo que respecta al cálculo de los reajustes e intereses de las sumas a las cuales se condena a la demandada, debe estimarse que en lo que respecta al daño emergente, los reajustes e intereses deben contabilizarse desde la notificación de la demanda interpuesta en estos autos y en lo que refiere al daño moral desde que queda ejecutoriada la sentencia definitiva" ${ }^{34}$.

\footnotetext{
${ }^{33}$ Ugarte Miranda y otros con Instituto Profesional Santo Tomás (2018).

${ }^{34}$ Op. cit. Sentencia de reemplazo.
} 
El reconocimiento del derecho de opción entre regímenes de responsabilidad como alternativa de solución a la concurrencia de responsabilidades reviste una doble importancia. En primer lugar, permite continuar consolidando jurisprudencialmente este criterio, zanjando una discusión que ha concitado la atención de nuestra doctrina desde antiguo ${ }^{35}$. En segundo lugar, se enmarca en la tendencia instaurada por el movimiento de modernización del Derecho de Obligaciones y Contratos, pues uno de los pilares en que este se cimienta es el derecho de opción del acreedor, cuyos fundamentos dogmáticos han sido asentados entre nosotros en sede contractual ${ }^{36}$ y precontractual ${ }^{37}$ (opción horizontal) y entre una y otra ${ }^{38}$ (opción vertical), superando la idea que la fuerza obligatoria impone la primacía del contrato $\mathrm{y}$, por consiguiente, del régimen contractual. Y es que, como ha indicado el profesor Carlos Pizarro ${ }^{39}$ no debe entenderse que dicho principio establece como vía de satisfacción del acreedor el cumplimiento del contrato, sino que consagra la facultad del acreedor para escoger el medio de tutela que le permita satisfacer su interés de mejor forma, premisa que deviene en un argumento adicional para sustentar la opción de responsabilidades, fortaleciendo, por consiguiente, su tutela.

La sentencia dictada por la Corte Suprema nos permite, entonces, efectuar dos constataciones. La primera es que la vía extracontractual parece ser la estrategia de protección más conveniente para el destinatario de la publicidad engañosa. La segunda, que la confianza razonable, principio cardinal del Derecho de Consumo ${ }^{40}$, que deviene en el fundamento de la integración publicitaria ${ }^{41}$, no constituye la única vía para tutelarlo, pues también es posible recurrir a una institución propia del Derecho Civil, cual es, la opción de responsabilidades, cuya admisibilidad nos permite seguir avanzando, como ha ocurrido, con otras $\operatorname{tantas}^{42}$, hacia la modernización del Derecho de Obligaciones y Contratos chileno.

\section{Bibliografía CITADA}

BARAONA GonZÁlez,Jorge (2014), "La regulación contenida en la Ley 19.496 sobre protección de los derechos de los consumidores y las reglas del Código Civil y

${ }^{35}$ Una completa sistematización en Domínguez (2008), pp. 717-734 y Corral (2010), pp. 639-653.

${ }^{36}$ LÓPEz (2015), pp. 104-125.

${ }^{37}$ López (2017), pp. 69-77.

${ }^{38}$ LÓPEZ (2017), pp. 69-77 y LÓPEz (2018).

${ }^{39}$ Pizarro (2008), p. 397.

${ }^{40}$ Una aproximación en nuestra doctrina en BARAONA (2014), pp. 388 y 393.

${ }^{41}$ Morales (2006a), p. 271 y De la Maza (2013b), pp. 448-451.

${ }^{42}$ Tales como la formulación de los deberes de información, la articulación de los medios de tutela precontractuales y anticipatorios al incumplimiento, la noción amplia, objetiva y neutra de incumplimiento y del incumplimiento resolutorio, el limitado alcance del caso fortuito, la cooperación del acreedor y la autonomía de la indemnización de daños. 
Comercial sobre contratos: un marco comparativo". Revista Chilena de Derecho $41, \mathrm{~N}^{\circ} 2$. Santiago.

Corral Talciani, Hernán (2010). "El concurso de responsabilidades en el derecho de daños chileno: defensa y delimitación de la teoría de la opción”, en DePARtamento de Derecho Privado Universidad de Concepción (coord.), Estudios de Derecho Civil V, Santiago, AbeledoPerrot LegalPublishing.

Corral, Hernán (2016). “'Cúmulo’ de responsabilidades: esperanzador giro jurisprudencial”. Análisis jurídico contratos y responsabilidad, Mercurio Legal, 23 de septiembre de 2016, en www.elmercurio.com/Legal/Noticias/AnalisisJuridico/2016/09/23/Cumulo-de-responsabilidades-esperanzador-giro-jurisprudencial.aspx\#.

De la Maza Gazmuri, Iñigo (2012). "Contrato de prestación de servicios educacionales e integración del contenido publicitario. Corte Suprema 11 de mayo de 2011. Revista chilena de derecho privado. $\mathrm{N}^{\circ} 19$, diciembre. Santiago.

De la Maza Gazmuri, Iñigo (2013a). “Artículo 28. Inducción a error o engaño del mensaje publicitario, en Iñigo De la Maza Gazmuri, Carlos Pizarro Wilson (eds.), Francisca Barrientos Camus (coord.). La Protección de los Derechos de los Consumidores. Comentario a la Ley de Protección a los derechos de los consumidores, Santiago, Thomson Reuters.

De la Maza Gazmuri, Iñigo (2013b) "La integración de la publicidad en el contrato”, en Carmen Domínguez Hidalgo, Joel González Castillo, Marcelo Barrientos Zamorano, Juan Luís Goldenberg Serrano (coords.), Estudios de Derecho Civil VIII, Santiago, LegalPublishing.

De la Maza Gazmuri, Iñigo (2015). "La integración publicitaria y la publicidad engañosa como supuesto de error provocado", en Manuel BARRÍA PAREDES, Bruno Caprile Biermann, José Luís Diez Schwerter, Carmen Domínguez Hidalgo, Carlos Pizarro Wilson, Mauricio Tapia Rodríguez (eds.), Estudios de Derecho Privado. Homenaje al profesor Ramón Domínguez Águila, Santiago, Thomson Reuters.

Domínguez Hidalgo, Carmen (2008). "La concurrencia de responsabilidades o el mal llamado cúmulo de responsabilidades en el derecho chileno: estado actual” en GuZmán Brito, Alejandro (editor científico). Estudios de Derecho Civil III. Santiago: Legalpublishig.

Isler Soto, Erika Marlene (2010) “Aproximación a la publicidad engañosa, desde la perspectiva de la competencia desleal y la protección al consumidor”. Revista Ars Boni et Aequi. № 6, Vol. 1. Santiago.

LóPez DíAz, Patricia Verónica (2015) La autonomía de la indemnización de daños por incumplimiento de un contrato bilateral en el Código Civil Chileno. Santiago: Editorial Thomson Reuters LegalPublishing.

López Díaz, Patricia Verónica (2017) "La tutela precontractual y contractual del acreedor en el Código Civil chileno: dos sistemas estructuralmente diversos, pero ¿plenamente coherentes y convergentes?”. Revista Chilena de Derecho Privado. $\mathrm{N}^{\circ}$ 29. Santiago. 
LóPez DíAz, Patricia Verónica (2018) “Tutela precontractual versus tutela contractual en el Código Civil chileno: ¿efecto espejo o reflejo?”. Estudios de Derecho Civil XIII, en prensa.

Momberg Uribe, Rodrigo (2007). "El rol de la publicidad en la etapa precontractual de los negocios de consumo y su relación con el principio de buena fe", en Hernán Corral Talciani, María Sara Rodríguez Pinto (coords.), Estudios de Derecho Civil II, Santiago, Lexis Nexis.

Morales Moreno, Antonio Manuel (2006a). "Declaraciones Públicas y vinculación contractual (Reflexiones sobre una Propuesta de Directiva”, en Antonio Manuel Morales Moreno. La modernización del derecho de obligaciones. Navarra: Thomson Civitas.

Morales Moreno, Antonio Manuel (2006b). "Información publicitaria y protección del consumidor (Reflexiones sobre el Art. $8^{\circ}$ de la LGCU)", en Antonio Manuel Morales Moreno. La modernización del derecho de obligaciones. Navarra: Thomson Civitas.

Morales Moreno, Antonio Manuel (2006c). "Los vicios de la voluntad en los Principios de Derecho Europeo de Contratos", en Antonio Manuel Morales Moreno. La modernización del derecho de obligaciones. Navarra: Thomson Civitas.

Pizarro Wilson, Carlos (2008). "Hacia un sistema de remedios al incumplimiento contractual”, en Alejandro GuZmán (ed.), Estudios de Derecho Civil III, Santiago, Editorial Lexis Nexis.

\section{Jurisprudencia citada}

Vidal Riquelme con Instituto Santo Tomás: Tercer Juzgado de Policía Local de Viña del Mar, 31 de agosto de 2010 (recurso de apelación). No disponible en buscador digital.

Vidal Riquelme con Instituto Santo Tomás: Corte de Apelaciones de Valparaíso, 4 de abril de 2012 (recurso de apelación), en www.vlex.com VLEX 634782393.

Celedón Fernández con Corporación Santo Tomás: Corte Suprema, 11 de mayo de 2012, (recurso de casación en la forma y casación en el fondo) en www. vlex.com VLEX-436187634.

Santos Pastenes y otros con Corporación Santo Tomás: Corte Suprema, 12 de diciembre de 2012 (recurso de casación en la forma) en www.vlex.com VLEX436275742.

González Valenzuela con Corporación Santo Tomás: Corte Suprema, 11 de mayo de 2012 (casación en la forma y en el fondo), en www.vlex.com Vlex-436187498.

Fernández con Arinoviche y otros: Corte Suprema, 21 de marzo de 2016 (casación en el fondo), en www.vlex.com, $\mathrm{N}^{\circ} 631574418$.

Ugarte Miranda y otros con Instituto Profesional Santo Tomás: Segundo Juzgado Civil de Viña del Mar, 14 de enero de 2016 (acción de indemnización extracontractual), disponible en http://civil.poderjudicial.cl/CIVILPORWEB/Down- 
loadFile.do?TIP_Documento=3\&TIP_Archivo=3\&COD_Opcion=1\&COD_ Tribunal=58\&CRR_IdTramite $=71594343 \&$ CRR_IdDocumento=63861280.

Zuñiga Castro con Instituto de Educación Superior Santo Tomás: Corte Suprema, 21 de julio de 2016, (recurso casación en el fondo) www.vlex.com VLEX 645516929.

Ugarte Miranda y otros con Instituto Profesional Santo Tomás: Corte de Apelaciones de Valparaíso, 25 de julio de 2016 (recurso de apelación), en www.vlex. com VLEX 646970813.

Ugarte Miranda y otros con Instituto Profesional Santo Tomás: Corte Suprema, 18 de enero de 2018 (recurso de casación en la forma y casación en el fondo), en www.vlex.com VLEX 701344085.

Ugarte Miranda y otros con Instituto Profesional Santo Tomás: Corte Suprema, 18 de enero de 2018 (recurso de casación en la forma y casación en el fondo). Sentencia de reemplazo, disponible en www.vlex.com VLEX 701344081. 